\title{
Differences in Skin Properties of Korean Women at the Initial Aging Phase
}

\author{
Gae Won Nam ${ }^{1}$, Eun Joo Kim ${ }^{1,2}$, Yu Chul Jung ${ }^{1}$, Choon Bok Jeong ${ }^{1}$, Kye Ho Shin ${ }^{1}$, Hae Kwang Lee ${ }^{1}$ \\ ${ }^{1}$ Skin Research Institute, Amorepacific R \& D Center, Yongin, Korea; ${ }^{2}$ Department of Dermatology, Chung-Ang University College \\ of Medicine, Seoul, Korea. \\ Email: skarod@amorepacific.com
}

Received January $7^{\text {th }}, 2014$; revised January $30^{\text {th }}, 2014$; accepted February $7^{\text {th }}, 2014$

Copyright (C) 2014 Gae Won Nam et al. This is an open access article distributed under the Creative Commons Attribution License, which permits unrestricted use, distribution, and reproduction in any medium, provided the original work is properly cited. In accordance of the Creative Commons Attribution License all Copyrights (C) 2014 are reserved for SCIRP and the owner of the intellectual property Gae Won Nam et al. All Copyright (C) 2014 are guarded by law and by SCIRP as a guardian.

\section{ABSTRACT}

Many studies on aging have focused on evaluating differences between older and younger people, but only a few have focused on differences in skin properties among subjects from the same age group according to their skin aging status. In this study, we evaluated the facial skin condition and life style factors in 110 Korean women aged 25 to 35 in an attempt to evaluate factors which may affect the skin aging status in the initial aging phase. The facial skin condition of 110 healthy Korean women was assessed over two successive 6-month periods, summer and winter. Using clinical assessments including aging, wrinkles and skin's elasticity values, the subjects were divided into 7 groups. Then, various facial skin conditions and life style factors were examined between a severe aging group and mild aging group. In the severe aging group, the mean value $\mathrm{pH}$ was lower and the mean value of water content was slightly lower than that of women in the mild aging group. Also, the seasonal site variation in water content and sebum secretion level were significantly higher in the severe aging group than in the mild aging group. Topical sunscreen using percentage was not significantly different between the two groups. However, the number of cosmetic subject use was slightly higher in the mild aging group than in the severe aging group. The study suggested that there were several differences in skin characteristics between women in the severe aging group and in the mild aging group at the initial aging phase. Seasonal site variation between cheek and forehead was the most dominant differences. We also considered that life style factors such as cosmetic use could affect skin aging status.

\section{KEYWORDS}

\section{Skin; Primary Aging; Korean Women; Water Content and Sebum Secretion}

\section{Introduction}

As people age, the appearance and characteristics of skin become altered [1]. In various medical fields such as dermatopathology, asthetic dermatology, and epistemology, it is essential to understand the changes that take place in aging facial skin because skin aging is particularly important for its social impact [2]. It is well known that there are 2 independent processes that influence skin aging: intrinsic and extrinsic aging. Intrinsic aging is an irreversible and inevitable process that occurs as a natural consequence of time. It is characterized by cellular senescence and decreased proliferative capacity, a decrease in cellular DNA repair capacity, oxidative stress, and gene mutation $[3,4]$. Extrinsic aging is the result of exposure to environmental factors, primarily ultraviolet irradiation [5,6]. Cigarette smoking, IR radiation, ozone and dust are also well known environmental factors that can affect skin aging [6-8]. In many previous skin aging studies, facial skin conditions were evaluated for various age generations, to comprehensively grasp their skin aging phenomena [9]. During the aging process, skin wrinkles and sagging increased due to a decrease in skin firmness. This has been proved through comparative studies between aging groups' elasticity [10] and wrinkle formation [11,12]. Therefore, wrinkle and sagging are considered to be the main phenomena of aging. However, 
besides age, other genetic factors and environmental factors influence the aging status.

In a previous study on skin aging differences between ethnic groups, skin characteristics show different changes or specific signs according to geographical conditions and phenotypic expression, reflection of different skin responses to the same stress or aging factor. Distinct skin features can be observed by comparing American-Caucasian with Japanese females [13] and French-Caucasian with Chinese [14]. Even within the same ethnic group, the facial signs of aging are affected by geographic and climatic factors such as latitude, temperature and humidity $[15,16]$. Even in the same regions, many other factors such as season and personal life styles influence skin aging $[2,17,18]$. Therefore, even in the same age group, skin aging condition varies depending on various factors. However, little is known about the skin characteristics and life factors that vary among people who look old and who look young but are at the same age.

This led us to focuse on the different characteristics of skin and lifestyle factors in women of the same age group according to their aging status. In this study, we classified 25 to 35 Korean women into 7 groups according to their aging status divided by wrinkle and elasticity and examined the differences between the most aging group and the least aging group's skin characteristics and lifestyle factors such as cosmetic use behavior.

\section{Materials and Methods}

\subsection{Study Population}

A total of 110 healthy women having lived in Yong-in city and aged between 25 and 35 were recruited for this study. They were each informed about the study protocol and asked to sign an informed consent form. Ethical approval was obtained from the Institutional Review Board of institute. All assessments were performed on bare skin, after 30 min acclimation in our facility maintained at a constant temperature and humidity $\left(\mathrm{T}=22^{\circ} \mathrm{C} \pm 1{ }^{\circ} \mathrm{C}, \mathrm{RH}\right.$ $=45 \% \pm 5 \%$ ). The assessments were performed in the winter and summer on the same participants.

\subsection{Biophysical Measurements}

Water content, sebum secretion, and skin elasticity were measured using Multiprobe Adapter Systems MPA580 (Courage \& Khazaka, Cologne, Germany). Skin hydration of cheek was measured using the Corneometer ${ }^{\circledR} \mathrm{CM}$ 825 (Courage + Khazaka Electronic GmbH, Cologne, Germany). Sebum of forehead was measured with Sebumeter $^{\circledR}$ SM 815 (Courage + Khazaka Electronic $\mathrm{GmbH})$. Surface $\mathrm{pH}$ was measured using a Skin $\mathrm{pH}$-meter ${ }^{\circledR}$ PH905(Courage \& Khazaka Electronic GmbH). Total epidermal water loss was measured using a vapometer (Delfinm, Finland). Skin elasticity was determined using
Cutometer $^{\circledR}$ MPA 580 (Courage + Khazaka Electronic $\mathrm{GmbH}$ ) and cheek R2 (the ratio of immediate retraction (Ur) to final distension (Uf) (Ur/Uf)) was used for Elasticity analysis. The melanin and erythema content was determined using Mexameter ${ }^{\circledR}$ MX18 (Courage \& Khazaka, Cologne, Germany). Wrinkle was measured in crow's feet area by replica method. At first, silicone replica of the craw's feet area was made using Silflo (Courage \& Khazaka, Cologne, Germany). Then, the relica was analyzed by Visoline VL650 (Courage \& Khazaka, Cologne, Germany). Total wrinkle area $\left(\mathrm{mm}^{2}\right)$, number of wrinkles, average wrinkle depth $(\mu \mathrm{m})$ and average wrinkle length $(\mathrm{mm})$ were measured.

\subsection{Self-Questionnaire}

Life style information was collected using a structured questionnaire. Age, educational background, alcohol consumption status, smoking status, marital status, education, sunscreen and cosmetic use behavior, sun exposal time per day, and main concerns related to skin condition were examined.

\subsection{Statistical Analysis}

All data were expressed as means \pm SEM. Differences among the groups were examined for statistical significance using ANOVA. Correlations among the results from each measurement were evaluated using Person's correlation coefficients. All calculations were performed using SPSS (version 10.0; SPSS Inc., Chicago, IL, USA) and MINITAB (LEAD Technologies, Inc. North Carolina, USA) Release 14.20. A P value of $<0.05$ was considered to indicate a significant difference.

\section{Results}

\subsection{Categorize Volunteers into 7 Groups According to Their Aging Status}

To investigate the different characteristics between severe aging people and mild aging people, we classified our volunteers according to their aging factor using cluster analysis. As wrinkle and elasticity were main aging parameters, we used total wrinkle area of crow's feet and cheek elasticity (R2: ratio of immediate retraction (Ur) to final distension (Uf)) for cluster analysis. By using clustering analysis (Minitab 14.20, Ward's method), we could divide volunteers into 7 groups depending on their wrinkle and elasticity degree (Figure 1). 7 aging groups show steady changes of aging parameters (Figure 2).

Table 1 show that characteristics of each group. Among those groups, group 1 was considered the mild aging group whereas group 7 was considered the severe aging group. Age shows steady increasing pattern. However, only G1 and G6 shows statistical differences ( $\mathrm{p}<$ 0.05, ANOVA Tukey HSD). 
Table 1. Characteristic of the groups classified in this study.

\begin{tabular}{|c|c|c|c|c|c|c|c|}
\hline \multirow{2}{*}{ Variable } & \multicolumn{7}{|c|}{ Value } \\
\hline & Group 1 & Group 2 & Group 3 & Group 4 & Group 5 & Group 6 & Group 7 \\
\hline Wrinkle area $\left(\mathrm{mm}^{2}\right)$ & 1.0 & 6.3 & 3.8 & 9.4 & 11.6 & 16.3 & 23.4 \\
\hline Cutometer R2 (Cheek) & 0.7 & 0.6 & 0.6 & 0.6 & 0.6 & 0.6 & 0.6 \\
\hline Age & $30.7^{*}$ & 32.1 & 32.6 & 32.7 & 34.0 & $34.1^{*}$ & 34.7 \\
\hline $\mathrm{n}$ & 10 & 15 & 33 & 15 & 10 & 21 & 6 \\
\hline
\end{tabular}

${ }^{*}$ Values indicates mean value of each group, ${ }^{*}$ Group 1 and Group 6 shows statistical age differences (p $<0.05$, ANOVA Tukey HSD).

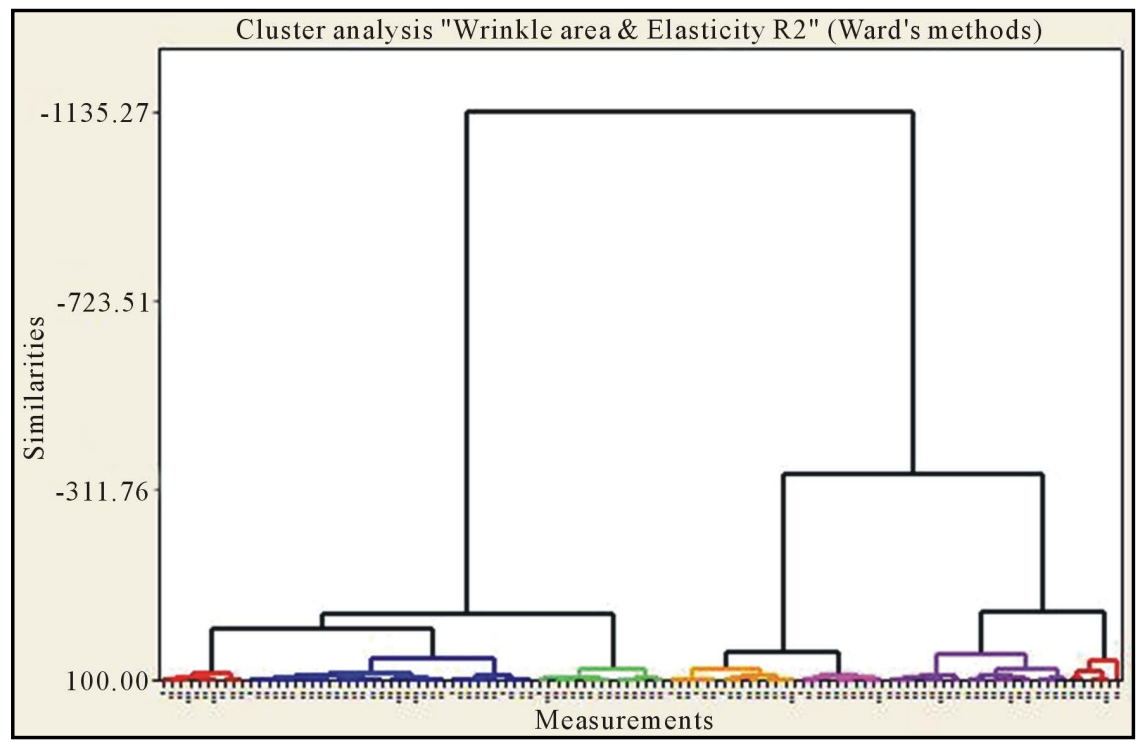

Figure 1. As a key aging parameter wrinkle area and elasticity R2 were used for clustering method. Volunteers were divided into 7 groups by cluster analysis.



Figure 2. Aging parameter changes among clustered groups. As aging group changes from group 1 to group 7, wrinkle area increases and elasticity decreases. 


\subsection{Seasonal Difference in Skin Condition between Mild Aging Group (Group 1) and Severe Aging Group (Group 7)}

To evaluate skin condition differences between aging groups, water content, sebum secretion, $\mathrm{pH}$, TEWL, melanin, and erythema were measured on the forehead and cheek. In the winter, severe aging group shows low moisturizing condition and $\mathrm{pH}$, and high TEWL compare with mild aging group. (Table 2) Sebum secretion of the cheek (33.40 \pm 4.20$)$ and forehead (39.4 \pm 5.1$)$ in mild aging group were higher than in severe aging group cheek $(16.83 \pm 4.53)$ and forehead $(26.5 \pm 5.7)$. Also, water content of the cheeks and foreheads in subjects from group 1 (cheek: $55.68 \pm 3.75$ ) (forehead: $61.26 \pm$ 2.24) were slightly higher than of the cheeks and foreheads of subjects from group 7 (cheek: $48.36 \pm 3.78$ ) (forehead: $55.18 \pm 2.24)$. $\mathrm{pH}$ of the cheek $(6.0 \pm 0.1)$ and forehead $(5.8 \pm 0.1)(0.05<\mathrm{p}$ value $<0.1)$ in mild aging group were higher than in severe aging group cheek (5.5 \pm 0.1 ) and forehead $(5.1 \pm 0.1)$ (Figure 3).

In the summer, severe aging group shows low moisturizing condition (cheek) and $\mathrm{pH}$, high TEWL compare with mild aging group (Table 3 ).

Water contest of the cheek (54.2 \pm 4.1$)$ in mild aging group were higher than in severe aging group ( $46.4 \pm 2.4)$

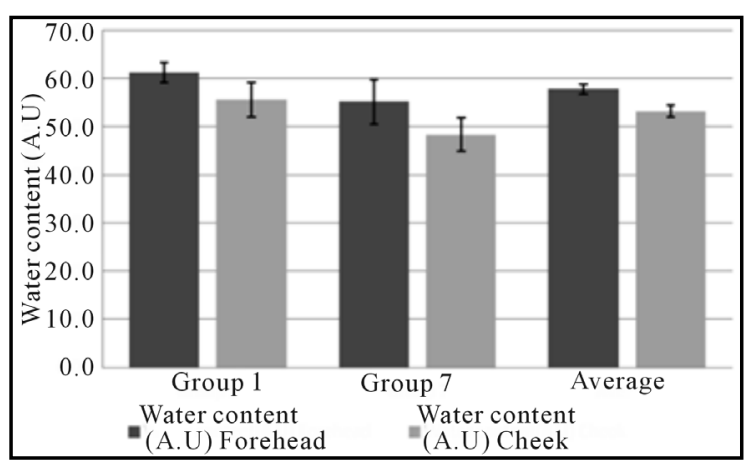

(a)



(c) $(0.05<\mathrm{p}<0.1)$. pH of the forehead $(5.5 \pm 0.1)$ in mild aging group were higher than in severe aging group (4.8 $\pm 0.1)(0.05<\mathrm{p}<0.1) . \mathrm{pH}$ and TEWL changes were similar in winter and summer. However moisturizing condition changes was different. Forehead shows increased water and sebum contents, but cheek shows decreased water and sebum contents (Figure 4). Eventually, moisturizing parameter differences between cheek and forehead were significantly higher in severe aging groups $(\mathrm{p}<0.05)$ (Table 4).

The variations from season (summer and winter) of skin condition were compared between groups. Melanin index shows seasonal differences, so we compared the fluctuation of melanin index in group 1 and group 7 . Comparing variation of melanin index in the summer and winter, the variation of group 1's melanin index in the forehead (34.96 \pm 5.56 ) was lower than group 7's melanin index in forehead (53.44 \pm 5.32 ). In addition, melanin index fluctuation of group 1's cheek (47.83 \pm 5.08$)$ was slightly lower than group 7's cheek melanin index fluctuation (60.61 \pm 7.76$)$ (Figure 5).

\subsection{Skin Condition Differences in Each Sites between Seasons}

Most of the parameters reveals significant differences

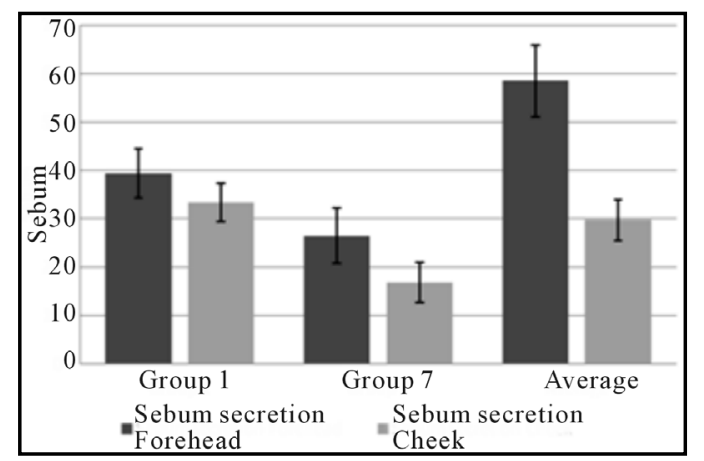

(b)



(d)

Figure 3. Skin condition differences between the mild aging group (group 1) and the most aging group (group 7) in winter. (a) Water content of cheek and forehead in group 1, 7, and total population; (b) Sebum secretion of cheek and forehead in group 1, 7, and total population; (c) pH of cheek and forehead in group 1, 7, and total population; (d) TEWL of cheek and forehead in group 1,7 , and total population. 


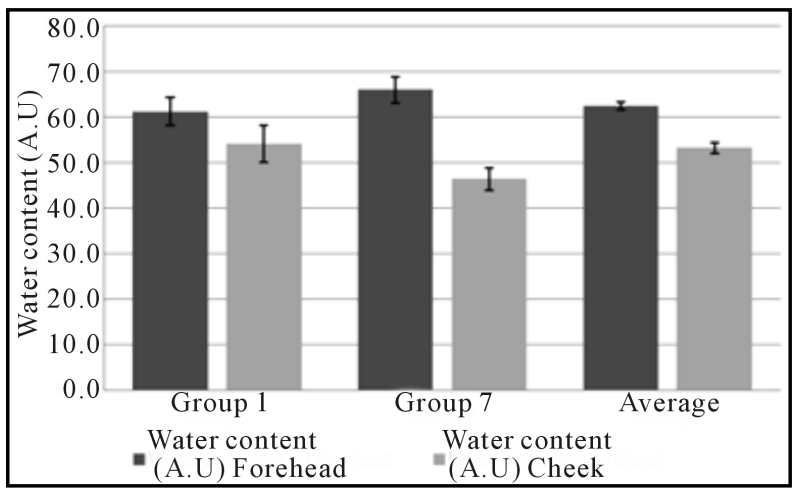

(a)

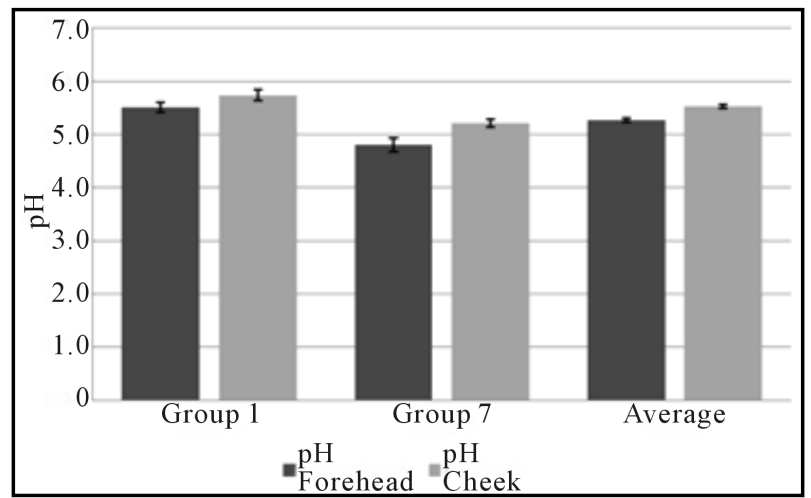

(c)

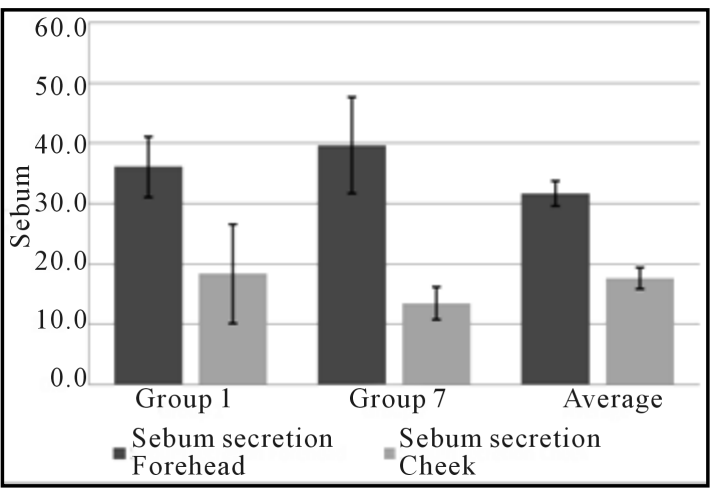

(b)

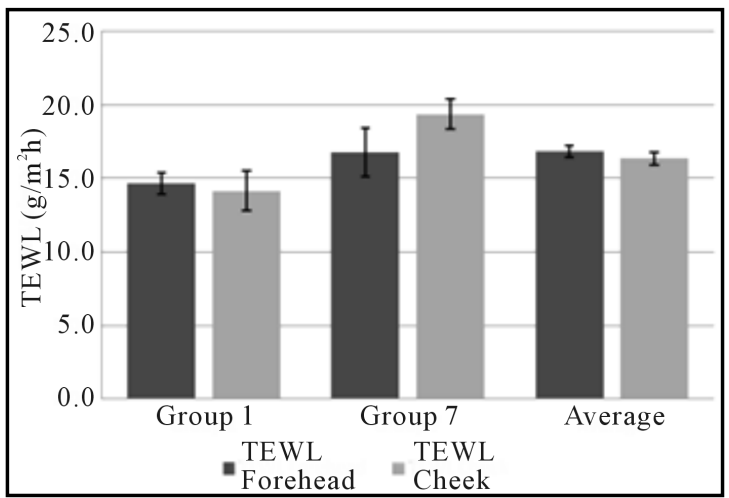

(d)

Figure 4. Skin condition differences between the mild aging group (group 1) and the most aging group (group 7) in summer. (a) Water content of cheek and forehead in group 1, 7, and total population; (b) Sebum secretion of cheek and forehead in group 1, 7, and total population; (c) pH of cheek and forehead in group 1, 7, and total population; (d) TEWL of cheek and forehead in group 1,7 , and total population.

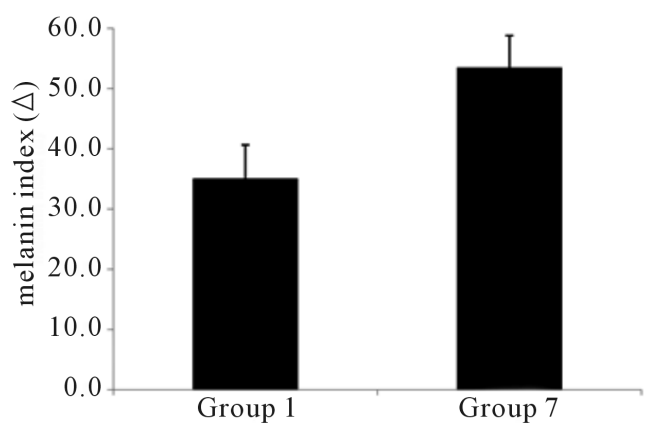

(a)



(b)

Figure 5. Seasonal variations in the melanin index of group 1 and 7. (a) Melanin index variation in the forehead of two groups; (b) Melanin index variation in the cheek of the two groups.

between seasons. Only few parameters (Water contents in cheek, TEWL in forehead, Elasticity in cheek) were not significantly changed. Water contents in forehead, Melanin, forehead elasticity were increased and sebum secretions, $\mathrm{pH}, \mathrm{TEWL}$, erythema, elasticity in check were decreased in summer (Table 5).

We also tested seasonal condition differences between groups, however there were no significant seasonal differences between groups.

\subsection{Cosmetic Usage Difference between Mild Aging Group (Group 1) and Severe Aging Group (Group 7)}

In order to investigate the effect of cosmetic usage behavior we compared manner of cosmetic usage differences between group 1 and group 7 using self questionnaire. The number of cosmetic products used in the morning and the evening is shown in Table 6. The number of 
Table 2. Skin characteristic differences between mild and severe aging group in the winter.

\begin{tabular}{|c|c|c|c|c|c|c|c|}
\hline Measurement & site & Group 1 & Group 7 & Average & Group 1 (SE) & Group 7 (SE) & Average (SE) \\
\hline \multirow{2}{*}{ Water content } & Forehead & 61.3 & 55.2 & 57.8 & 2.1 & 4.6 & 1.1 \\
\hline & Cheek & 55.7 & 48.4 & 53.2 & 3.6 & 3.5 & 1.2 \\
\hline \multirow{2}{*}{ Sebum secretion } & Forehead & 39.4 & 26.5 & 58.5 & 5.1 & 5.7 & 7.4 \\
\hline & Cheek & 33.4 & 16.8 & 29.8 & 4.0 & 4.1 & 4.3 \\
\hline \multirow{2}{*}{$\mathrm{pH}$} & Forehead & 5.8 & 5.1 & 5.5 & 0.1 & 0.2 & 0.0 \\
\hline & Cheek & 6.0 & 5.5 & 5.7 & 0.1 & 0.1 & 0.0 \\
\hline \multirow{2}{*}{ TEWL } & Forehead & 16.6 & 18.5 & 16.7 & 0.9 & 2.1 & 0.4 \\
\hline & Cheek & 17.4 & 21.1 & 18.4 & 1.6 & 2.3 & 0.5 \\
\hline \multirow{2}{*}{ Melanin } & Forehead & 170.9 & 178.0 & 171.4 & 7.9 & 14.4 & 3.1 \\
\hline & Cheek & 121.9 & 117.5 & 116.0 & 9.2 & 10.2 & 2.2 \\
\hline \multirow{2}{*}{ Erythema } & Forehead & 297.7 & 280.2 & 273.5 & 17.2 & 24.3 & 5.2 \\
\hline & Cheek & 292.6 & 267.9 & 268.3 & 20.9 & 28.8 & 5.2 \\
\hline \multirow{2}{*}{ Elasticity (R2) } & Forehead & 0.58 & 0.54 & 0.58 & 0.03 & 0.02 & 0.01 \\
\hline & Cheek & 0.67 & 0.58 & 0.63 & 0.02 & 0.03 & 0.01 \\
\hline
\end{tabular}

Table 3. Skin characteristic differences between mild and severe aging group in the summer.

\begin{tabular}{|c|c|c|c|c|c|c|c|}
\hline Measurement & site & Group 1 & Group 7 & Average & Group 1 (SE) & Group 7 (SE) & Average (SE) \\
\hline \multirow{2}{*}{ Water content } & Forehead & 61.2 & 66.0 & 62.4 & 3.1 & 2.8 & 0.8 \\
\hline & Cheek & 54.2 & 46.4 & 53.2 & 4.1 & 2.4 & 1.1 \\
\hline \multirow{2}{*}{ Sebum secretion } & Forehead & 36.1 & 39.7 & 31.7 & 5.0 & 8.0 & 2.1 \\
\hline & Cheek & 18.4 & 13.5 & 17.7 & 8.2 & 2.7 & 1.7 \\
\hline \multirow{2}{*}{$\mathrm{pH}$} & Forehead & 5.5 & 4.8 & 5.3 & 0.1 & 0.1 & 0.0 \\
\hline & Cheek & 5.7 & 5.2 & 5.5 & 0.1 & 0.1 & 0.0 \\
\hline \multirow{2}{*}{ TEWL } & Forehead & 14.7 & 16.8 & 16.8 & 0.7 & 1.7 & 0.4 \\
\hline & Cheek & 14.2 & 19.4 & 16.4 & 1.4 & 1.0 & 0.4 \\
\hline \multirow{2}{*}{ Melanin } & Forehead & 211.9 & 231.4 & 203.2 & 9.3 & 14.4 & 3.1 \\
\hline & Cheek & 182.9 & 178.1 & 165.8 & 5.4 & 12.8 & 2.8 \\
\hline \multirow{2}{*}{ Erythema } & Forehead & 279.3 & 276.9 & 264.0 & 14.4 & 19.9 & 4.7 \\
\hline & Cheek & 263.1 & 219.9 & 223.8 & 12.6 & 9.2 & 6.3 \\
\hline \multirow{2}{*}{ Elasticity(R2) } & Forehead & 0.61 & 0.63 & 0.64 & 0.02 & 0.02 & 0.01 \\
\hline & Cheek & 0.62 & 0.56 & 0.61 & 0.02 & 0.03 & 0.01 \\
\hline
\end{tabular}

cosmetic products in the morning in group 1 was slightly higher than in group 7.

In terms of sunscreen usage, there were no significant differences between the two groups. A total of $70 \%$ of group 1 used sunscreen whereas $66.7 \%$ of group 2 used sunscreen. In addition, cosmetic usage behavior differences by season were not significantly different between two groups.

\section{Discussion}

In this study, the skin condition and cosmetic use beha- vior of 110 healthy women aged $25 \sim 35$ were assessed. In order to examine skin condition and cosmetic use behavior that may cause accelerated skin aging, participants were divided into 7 groups according to their aging status determined wrinkling and loss of elasticity.

Wrinkles reflect skin structure changes caused by deterioration of dermal physical structure such as elastin and collagen in the dermal layer [19,20]. Also, three layer of skin (epidermis, dermis and subcutaneous layer) thickness changed during the aging process, which caused alternation in skin mechanical properties. The 
Table 4. Moisturizing parameter differences between forehead and cheek in each season.

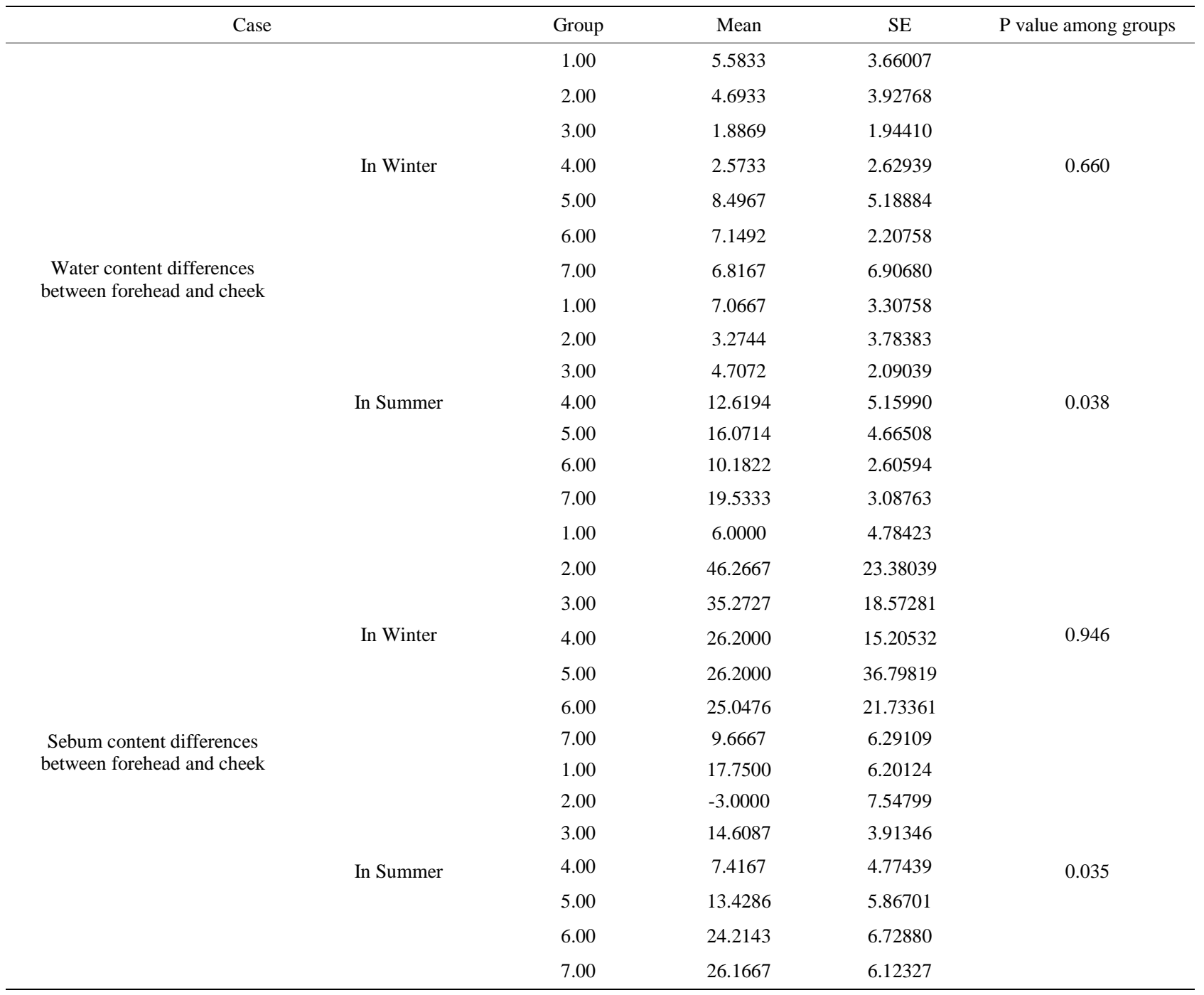

Table 5. Skin characteristic differences between seasons (Ave: Average, SE: Standard error).

\begin{tabular}{|c|c|c|c|c|c|c|}
\hline Measurements & Site & Winter (Ave) & Winter (SE) & Summer (Ave) & Summer (SE) & $\mathrm{P}$ value \\
\hline \multirow{2}{*}{ Water content (AU) } & Forehead & 56.94 & 1.25 & 62.45 & 1.00 & $0.00^{* * *}$ \\
\hline & Cheek & 53.13 & 1.44 & 53.23 & 1.33 & 0.95 \\
\hline \multirow{2}{*}{ Sebum secretion } & Forehead & 60.35 & 8.95 & 31.73 & 2.51 & $0.00^{*}$ \\
\hline & Cheek & 26.67 & 4.58 & 17.65 & 2.02 & $0.05^{*}$ \\
\hline $\mathrm{pH}$ & Forehead & 5.55 & 0.06 & 5.26 & 0.05 & $0.00^{* * *}$ \\
\hline \multirow{2}{*}{ TEWL } & Forehead & 17.08 & 0.46 & 16.84 & 0.50 & 0.67 \\
\hline & Cheek & 18.47 & 0.57 & 16.36 & 0.50 & $0.00^{* *}$ \\
\hline \multirow{2}{*}{ Melanin index } & Forehead & 170.13 & 3.37 & 203.20 & 3.63 & $0.00^{* * *}$ \\
\hline & Cheek & 116.24 & 2.47 & 165.83 & 3.30 & $0.00^{* * *}$ \\
\hline Erythema index & Forehead & 272.04 & 5.93 & 263.99 & 5.64 & $0.03^{*}$ \\
\hline \multirow{2}{*}{ Cutometer R2 } & Forehead & 0.59 & 0.01 & 0.64 & 0.01 & $0.00^{*}$ \\
\hline & Cheek & 0.63 & 0.01 & 0.61 & 0.01 & 0.05 \\
\hline
\end{tabular}

${ }_{\mathrm{p}}^{*}<0.05 ;{ }^{* *} \mathrm{p}<0.01 ;{ }^{* * *} \mathrm{p}<0.001$ 
Table 6. Number of cosmetic use differences between mild and severe aging groups.

\begin{tabular}{cccc}
\hline & Mean & SE & P value \\
\hline Group 1 & 7.00 & 0.97 & 0.054 \\
Group 7 & 3.83 & 1.08 & \\
\hline
\end{tabular}

previous study using suction chamber methods, defined high correlation with age and skin mechanical properties [10]. As a result, wrinkles and elasticity highly correlated to skin aging and were appropriate for use as a facial skin aging index.

Using cluster analysis, participants were divided into 7 distinct groups according to their wrinkle and elasticity. Among various factors related to wrinkles, total wrinkle area was used for classification and cheek R2 was used as an elasticity indicator. Participants were aged from 25 to 35 which were considered as the initial aging phase in order to determine differences in factors which may enhance skin aging.

The study reported here indicates that among the initial aging groups, there are differences in skin characteristics and cosmetic use behavior between the severe aging group and mild aging groups. In the severe aging group, cheek water content and forehead $\mathrm{pH}$ was lower than in the mild aging group in summer $(0.05<\mathrm{p}<0.1)$. With regards to seasonal differences in skin condition, site differences in the moisturizing parameter (water content and sebum secretion level) of the severe aging group were higher than that of the mild aging group. In terms of cosmetic use, the mild aging group used more cosmetics during the day than the mild aging group.

From practical and applied aspects, this result has important consequences. Comparing skin characteristics and life style factors between the severe aging group and the mild aging group at the initial aging phase, we noticed that there were different properties in several skin characteristics and cosmetic usage. Whether these different factors cause skin aging status differences or results of skin aging status differences still remains to be investigated, we suggest that people with dry type skin, high seasonal variation and low use of cosmetics possibly also have more wrinkles and low elasticity. In addition, relationship of skin aging at initial phase and their middle and late phase still needs to be investigated.

Taken together, the results from this study shows that physical skin properties including moisturizing condition seasonal differences, and cosmetic use behavior were different between mild skin aging group and the severe skin aging group even in the same age groups. To summarize, the mild skin aging group and the severe skin aging group show differences in skin conditions and cosmetic use behavior at the initial aging phase.

\section{Conclusion}

The study suggested that there were several differences in skin characteristics between women in the severe aging group and in the mild aging group at the initial aging phase. Seasonal site variations between cheek and forehead were the most dominant differences. We also considered that life style factors such as cosmetic use could affect skin aging status.

\section{REFERENCES}

[1] T. M. Callaghan and K. P. Wilhelm, "A Review of Ageing and an Examination of Clinical Methods in the Assessment of Ageing Skin. Part 2: Clinical Perspectives and Clinical Methods in the Evaluation of Ageing Skin," International Journal of Cosmetic Science, Vol. 30, No. 5, 2008, pp. 323-332. http://dx.doi.org/10.1111/j.1468-2494.2008.00455.x

[2] D. A. Gunn, H. Rexbye, C. E. Griffiths, P. G. Murray, A. Fereday, S. D. Catt, C. C. Tomlin, B. H. Strongitharm, D. I. Perrett, M. Catt, A. E. Mayes, A. G. Messenger, M. R. Green, F. van der Ouderaa, J. W. Vaupel and K. Christensen, "Why Some Women Look Young for Their Age," PLoS One, Vol. 4, No. 12, 2009, Article ID: e8021. http://dx.doi.org/10.1371/journal.pone.0008021

[3] J. Uitto, “Understanding Premature Skin Aging," New England Journal of Medicine, Vol. 337, No. 20, 1997, pp. 1463-1465. http://dx.doi.org/10.1056/NEJM199711133372011

[4] M. A. Farage, K. W. Miller, P. Elsner and H. I. Maibach, "Intrinsic and Extrinsic Factors in Skin Ageing: A Review," International Journal of Cosmetic Science, Vol. 30, No. 2, 2008, pp. 87-95.

http://dx.doi.org/10.1111/j.1468-2494.2007.00415.x

[5] L. Yin, A. Morita and T. Tsuji, "Skin Aging Induced by Ultraviolet Exposure and Tobacco Smoking: Evidence from Epidemiological and Molecular Studies," Photodermatology, Photoimmunology \& Photomedicine, Vol. 17, No. 4, 2001, pp. 178-183. http://dx.doi.org/10.1034/j.1600-0781.2001.170407.x

[6] W. C. Leung and I. Harvey, "Is Skin Ageing in the Elderly Caused by Sun Exposure or Smoking?” British Journal of Dermatology, Vol. 147, No. 6, 2002, pp. 11871191. http://dx.doi.org/10.1046/j.1365-2133.2002.04991.x

[7] S. Cho, M. H. Shin, Y. K. Kim, J. E. Seo, Y. M. Lee, C. H. Park and J. H. Chung, "Effects of Infrared Radiation and Heat on Human Skin Aging in Vivo," Journal of Investigative Dermatology Symposium Proceedings, Vol. 14, No. 1, 2009, pp. 15-19. http://dx.doi.org/10.1038/jidsymp.2009.7

[8] V. L. Ernster, D. Grady, R. Miike, D. Black, J. Selby and K. Kerlikowske, "Facial wrinkling in men and women, by smoking status,” Am J Public Health. Vol. 85, No. 1, 1995, pp. 78-82. http://dx.doi.org/10.2105/AJPH.85.1.78

[9] J. M. Waller and H. I. Maibach, "Age and Skin Structure and Function, a Quantitative Approach (I): Blood Flow, $\mathrm{pH}$, Thickness, and Ultrasound Echogenicity," Skin Research and Technology, Vol. 11, No. 4, 2005, pp. 221- 
235. http://dx.doi.org/10.1111/j.0909-725X.2005.00151.x

[10] N. Krueger, S. Luebberding, M. Oltmer, M. Streker and M. Kerscher, "Age-Related Changes in Skin Mechanical Properties: A Quantitative Evaluation of 120 Female Subjects," Skin Research and Technology, Vol. 17, No. 2, 2011, pp. 141-148.

http://dx.doi.org/10.1111/j.1600-0846.2010.00486.x

[11] T. Fujimura, K. Haketa, M. Hotta and T. Kitahara, "Loss of Skin Elasticity Precedes to Rapid Increase of Wrinkle Levels,” Journal of Dermatological Science, Vol. 47, No. 3, 2007, pp. 233-239.

http://dx.doi.org/10.1016/j.jdermsci.2007.05.002

[12] G. J. Fisher, J. Varani and J. J. Voorhees, "Looking Older: Fibroblast Collapse and Therapeutic Implications," Archives of Dermatology, Vol. 144, No. 5, 2008, pp. 666-672. http://dx.doi.org/10.1001/archderm.144.5.666

[13] K. Tsukahara, T. Fujimura, Y. Yoshida, T. Kitahara, M. Hotta, S. Moriwaki, P. S. Witt, F. A. Simion and Y. Takema, "Comparison of Age-Related Changes in Wrinkling and Sagging of the Skin in Caucasian Females and in Japanese Females,” Journal of Cosmetic Science, Vol. 55, No. 4, 2004, pp. 351-371.

[14] S. Nouveau-Richard, Z. Yang, S. Mac-Mary, L. Li, P. Bastien, I. Tardy, C. Bouillon, P. Humbert and O. de Lacharrière, "Skin Ageing: A Comparison between Chinese and European Populations: A Pilot Study,” Journal of Dermatological Science, Vol. 40, No. 3, 2005, pp. 187-193. http://dx.doi.org/10.1016/j.jdermsci.2005.06.006

[15] K. Tsukahara, K. Sugata, O. Osanai, A. Ohuchi, Y. Miyauchi, M. Takizawa, M. Hotta and T. Kitahara, "Comparison of Age-Related Changes in Facial Wrinkles and Sagging in the Skin of Japanese, Chinese and Thai Women," Journal of Dermatological Science, Vol. 47, No. 1, 2007, pp. 19-28.

http://dx.doi.org/10.1016/j.jdermsci.2007.03.007

[16] G. G. Hillebrand, K. Miyamoto, B. Schnell, M. Ichihashi, R. Shinkura and S. Akiba, "Quantitative Evaluation of Skin Condition in an Epidemiological Survey of Females Living in Northern versus Southern Japan," Journal of Dermatological Science, Vol. 27, No. S1, 2001, pp. S42S52. http://dx.doi.org/10.1016/S0923-1811(01)00118-9

[17] K. Asakura, Y. Nishiwaki, A. Milojevic, T. Michikawa, Y. Kikuchi, M. Nakano, S. Iwasawa, G. Hillebrand, K. Miyamoto, M. Ono, Y. Kinjo, S. Akiba and T. Takebayashi, "Lifestyle Factors and Visible Skin Aging in a Population of Japanese Elders,” Journal of Epidemiology, Vol. 19, No. 5, 2009, pp. 251-259. http://dx.doi.org/10.2188/jea.JE20090031

[18] H. Qiu, X. Long, J. C. Ye, J. Hou, J. Senee, A. Laurent, R. Bazin, F. Flament, A. Adam, J. Coutet and B. Piot, "Influence of Season on Some Skin Properties: Winter vs. Summer, as Experienced by 354 Shanghaiese Women of Various Ages,” International Journal of Cosmetic Science, Vol. 33, No. 4, 2011, pp. 377-383. http://dx.doi.org/10.1111/j.1468-2494.2011.00639.x

[19] G. Imokawa, "Recent Advances in Characterizing Biological Mechanisms Underlying UV-Induced Wrinkles: A Pivotal Role of Fibrobrast-Derived Elastase," Archives of Dermatological Research, Vol. 300, No. S1, 2008, pp. S7-S20. http://dx.doi.org/10.1007/s00403-007-0798-X

[20] S. Imayama and I. M. Braverman, "A Hypothetical Explanation for the Aging of Skin. Chronologic Alteration of the Three-Dimensional Arrangement of Collagen and Elastic Fibers in Connective Tissue," American Journal of Pathology, Vol. 134, No. 5, 1989, pp. 1019-1025. 